\title{
Design Guidelines for Coffee Vending Machines
}

\author{
Tim Schneidermeier, Manuel Burghardt, Christian Wolff \\ Media Informatics Group, University of Regensburg \\ \{tim.schneidermeier, manuel.burghardt, christian.wolff\}@ur.de
}

\begin{abstract}
Walk-up-and-use-systems such as vending and self-service machines request special attention concerning an easy to use and self-explanatory user interface. In this paper we present a set of design guidelines for coffee vending machines based on the results of an expert-based usability evaluation of thirteen different models.
\end{abstract}

Keywords. usability, user experience, vending machine, public space, case study, walk-up-and-use-system

\section{Introduction}

High demands have to be made on interactive devices in public spaces with respect to an easy-to-use and user-friendly interface. In particular appliances that have to be used ad hoc and without any further instructions need to be designed in a selfexplanatory way (Saffer 2012). Consumer electronics (CE) such as cameras, TV sets, or mobile phones are delivered with detailed manuals that explain the whole range of features including the necessary interaction steps. At least in theory, the customer is able to study the manual and make himself familiar with the device before actually using it. Self-service and vending machines, especially in public spaces, in contrast need to be operated instantly without any help, typically in situations with additional stress factors like time and social pressure. Usability therefore plays an important role for a positive user experience (Thimbleby et al. 2002). Although there are many studies concerning the usability of walk-up-and-use systems (e.g. Bratteberg \& Kristoffersen 2008; Camilli et al. 2011; Connell, Blandford \& Green 2004; Lee 2003) we still have to deal with hard to use ticket and vending machines in everyday life.

Coffee is one of the most-consumed beverages in the world (Villanueva et al. 2006) - and so is the case for the campus of the University of Regensburg, Germany (http://www.ur.de). ${ }^{1}$ This paper discusses the results of a study concerning the overall usability of various coffee vending machines around the campus. The goal was to systematically identify usability problems according to a predefined set of heuristics and derive guidelines for a pleasurable and easy to use coffee vending machine.

1 In 2011 a total of 700.000 cups of (fair trade) coffee were purchased at coffee vending machines around the campus (based on data gained from the campus office, August, 2012). 


\section{$2 \quad$ Study Design}

We used a heuristic walkthrough (Sears 1997) - an expert-based method that combines a heuristic evaluation (Nielsen \& Molich 1990) with elements of a cognitive walkthrough (Wharton et al. 1994) - to test usability. The heuristic walkthrough is conducted in two steps: In a first, task-oriented evaluation a usability expert uses typical usage scenarios to explore the product from a user's point of view. In a second step the device is additionally analyzed by means of a predefined set of usability heuristics. The initial data gathering was supplemented by user interviews and observational research. The goal was not only to discover usability problems, but also to record good, i.e. user-friendly, solutions for typical tasks on coffee vending machines (e.g. purchasing a cup of coffee adapted to one's preferences). Altogether thirteen different models of coffee vending machines produced by seven different manufacturers were included in this study (see Figure 1 for examples).

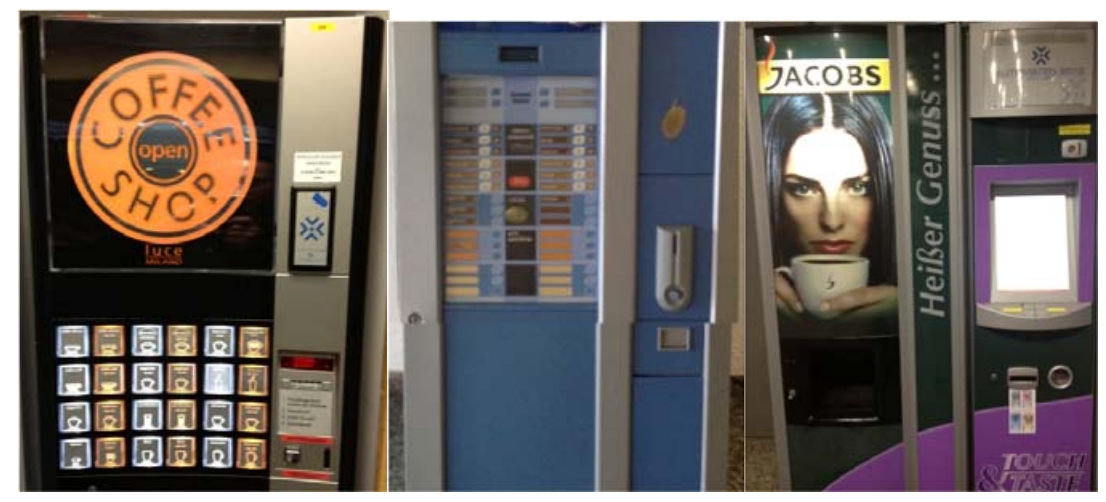

Fig. 1. Three of the thirteen different coffee vending machine models analyzed in this study.

Each vending machine was tested by two independent evaluators ${ }^{2}$. The usability problems identified in the walkthrough were assigned to a predefined set of heuristics for everyday devices ${ }^{3}$. The set consists of the following ten items:

(1) Consistency

(2) Feedback

2 The evaluators were undergraduate students from the media informatics B. A. degree program (http://mi.ur.de). They had received training in usability engineering methods, in particular in the heuristic walkthrough method, in advance. They were also trained in generic user interface design guidelines as well as the heuristics for everyday devices.

3 The heuristics for everyday devices have been developed in the context of a master thesis at the Media Informatics Group, University of Regensburg. They are based on a broad literature review of relevant sets of heuristics and validated by means of user tests (cf. Böhm 2011; publication planned for 2013). 

(3) Ease-of-use
(4) Error tolerance
(5) Suitability for the task
(6) Help and documentation
(7) Self-descriptiveness
(8) Simplicity
(9) Universal and flexible design
(10) Hedonic quality

During a one-day workshop, which included all usability analysts involved in the project, the identified problems were ranked by their frequency as well as their severity in order to determine the most critical ones. Most of them were assigned to (2) feedback, (9) universal and flexible design and (10) hedonic quality. Table 1 shows examples of some of the most severe problems.

Table 1. Overview of the most severe usability problems.

\begin{tabular}{|l|l|}
\hline Heuristic & Usability problem \\
\hline (1) Consistency & $\begin{array}{l}\text { Multiple buttons result in the same action (e.g. order- } \\
\text { ing a café au lait). }\end{array}$ \\
\hline (2) Feedback & Cryptic error messages. \\
\hline (3) Ease-of-use & $\begin{array}{l}\text { Most vending machines are not operable with one } \\
\text { hand. }\end{array}$ \\
\hline (4) Error tolerance & $\begin{array}{l}\text { The ordering process is dominated by the machine, not } \\
\text { the user: for instance, the consumer needs to choose } \\
\text { the amount of sugar before he can choose the actual } \\
\text { beverage. A subsequent customization is not support- } \\
\text { ed. }\end{array}$ \\
\hline (5) Suitability for the task & $\begin{array}{l}\text { Different products are not easy to distinguish (e.g. } \\
\text { form, color, image). }\end{array}$ \\
\hline (6) Help and documentation & There is no documentation, e.g. about the ingredients. \\
\hline (7) Self-descriptiveness & $\begin{array}{l}\text { Labels of the control elements do not represent the } \\
\text { action (e.g. "start"). }\end{array}$ \\
\hline (8) Simplicity & $\begin{array}{l}\text { Information shown on the display is not related to the } \\
\text { task. }\end{array}$ \\
\hline $\begin{array}{l}\text { (9) Universal and flexible } \\
\text { design }\end{array}$ & $\begin{array}{l}\text { Vending machines often do not meet the requirements } \\
\text { of accessibility. }\end{array}$ \\
\hline (10) Hedonic quality & $\begin{array}{l}\text { Visual design, aesthetic appearance as well as the } \\
\text { cleanliness of the vending machines were judged to } \\
\text { have a great deal of room for improvement. }\end{array}$ \\
\hline
\end{tabular}

Based on these results as well as the discovered good design solutions for typical tasks, requirements for an easy-to-use and pleasurable coffee vending machine were collaboratively derived during the workshop (see Figure 2). In a first step each evaluator puts all requirements identified in the heuristic walkthrough on Post-its (one 
requirement per Post-it) and assigned each requirement to the heuristics for everyday devices. In a second step similar labels were standardized and related requirements were grouped together. In a third step the requirements in each group were ranked by priority, resulting in a categorized and ranked list of requirements.

In addition to purely pragmatic, i.e. functional, usability aspects, particularly hedonic, i.e. experience-oriented (Hassenzahl 2003), aspects to design for an overall good user experience have been taken into account. The requirements were documented in the form of design guidelines and assigned to the set of heuristics for everyday devices.
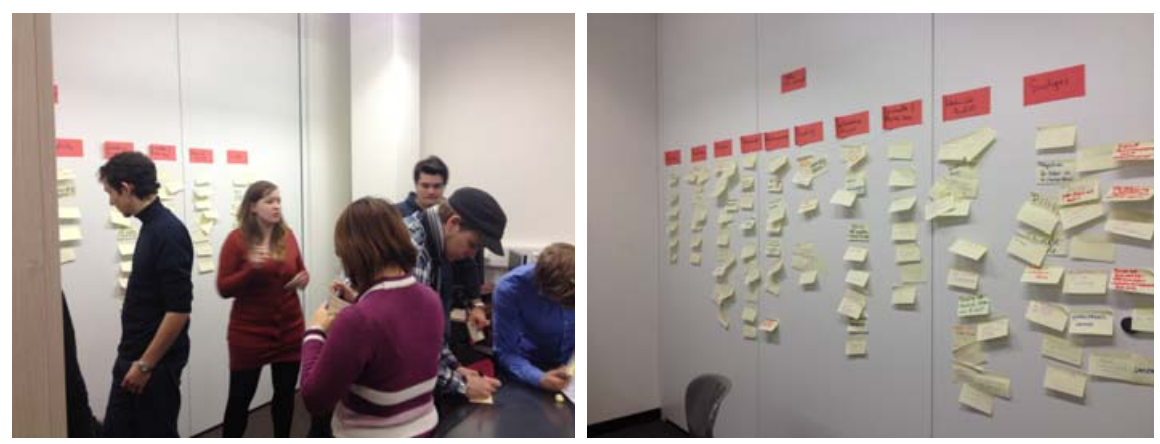

Fig. 2. Collaborative requirements workshop.

\section{Design guidelines for coffee vending machines}

In this section we discuss the requirements that were identified for user-friendly coffee vending machines. In general, we can distinguish between two kinds of requirements: (a) Those which address the vending machine and its user interface, and (b) those which include social and physical contextual factors. Please note that the guidelines listed below do not claim to be exhaustive, but rather represent the results of the study presented in this paper.

\section{(1) Consistency}

- [1.1] Labels and wording used for control elements, product names and description etc. on the machine surface (e.g. control elements) should match the ones used on the display.

\section{(2) Feedback}

- [2.1] The vending machine should always display its system status (ready to use beverage selected - preparing beverage (supported e.g. by a progress bar) - beverage is ready). 
- [2.2] Besides a visual feedback, critical system status should also be signaled acoustically. This is especially important for occurring errors and when the ordering process is finished.

- [2.3] Feedback and error messages should speak the users` language and provide information about what to do (e.g. refill coffee beans).

- [2.4] The price for each product should be shown before the start of the ordering process (e.g. by pushing a button the prize of the selected beverage is shown on the display).

- [2.5] The status of each product (in stock, out of stock) should be clearly visible and distinguishable.

\section{(3) Ease-of-use}

- [3.1] Each product should be represented by one control element and be available with a single click.

- [3.3] Customization of the product (e.g. amount of sugar) should be allowed at any time of the ordering process.

- [3.4] The amount of extra sugar and milk should be presented on a scale that meets the users` mental models (e.g. table spoons of sugar, drops of concentrated milk).

\section{(4) Error tolerance}

- [4.1] The beverage should only be served when cups are in stock (if the machine is out of cups a meaningful error message should be displayed).

- [4.2] The user should have the option to cancel the order process or undo his action (e.g. selected amount of sugar) within a short period (i.e. some seconds) of time after initiating the action.

\section{(5) Suitability for the task}

- [5.1] All control elements should be recognizable as such at first glance.

- [5.2] Pushing a button to select a specific product and start the ordering process should be supported with an adequate haptic feedback to confirm the success of the task.

- [5.3] If there are several options for one product (e.g. different sizes) the according control elements should be grouped in a way that consumers can easily identify associated elements (e.g. color, form, adjustment).

- [5.4] Size, contrast and luminance of the display should be designed in a way that the information is easily readable, even in a bright public space.

\section{(6) Help and documentation}

- [6.1] Information about the products and their ingredients should be accessible for the consumer (crucial information for intolerances or allergies).

\section{(7) Self-descriptiveness}


- [7.1] Buttons for each product should be labeled with self-explanatory text (e.g. the name of the product) as well as a symbolic representation of the product (e.g. a small cup indicating an espresso).

- [7.2] The range of products to choose from should adapt itself to the available credit (e.g. when 80 Cents are inserted, only products for 80 cents or less can be selected). This could be displayed with an enlightened button, for example.

- [7.3] Different products should be distinguishable at first glance (label, image).

\section{(8) Simplicity}

- [8.1] There should be a one-to-one relationship between control element and function, i.e. each product can be selected pushing exactly one specific button.

- [8.2] The overall design of the input and output elements as well as the paying mechanism should be well structured, ordered and designed in a task supporting way.

- [8.3] Information displayed on screen should be task relevant (e.g. the date may be unnecessary information, whereas the status of the system, e.g. ready to take the consumers`order is relevant for the task).

\section{(9) Universal and flexible design}

- [9.1] The vending machine should be designed in a way that matches the requirements of accessibility, i.e. all control elements and the actual beverage should also be reachable from a wheelchair.

- [9.2] The vending machine should be operable with one hand (e.g. when the consumer is packed with a bag, books, etc.).

- [9.3] The machine should be operable by all users, regardless to their cultural and linguistic background.

- [9.4] The user should be able to adapt the beverages to his preferences (e.g. size, strength, sugar, milk).

- [9.5] The user should have the opportunity to use his own cup instead of the ones provided by the vending machine.

\section{(10) Hedonic quality}

- [10.1] All five senses should be addressed to provide an optimal experience:

- Hearing: grinding coffee beans

- Sight: visible coffee beans

- Touch: comfortable and heat-resisting cup, preferably not made of cheap plastic

- Smell: freshly brewed coffee, the flavor of freshly ground coffee beans

- Taste: delicious, high-quality coffee

- [10.2] The visual design of the vending machine should be aesthetically appealing (e.g. color, labels).

- [10.3] Price and quality of the coffee should be in concordance.

- [10.4] The vending machine should be located at a suitable position

- Enough space to queue when necessary

- Easily reachable 
- [10.5] The products should support special diets and interests (e.g. lactose-free, organic ingredients, decaffeinated, amount of calories).

- [10.6] The actual product should look alike to the visual representation used as the label to describe the product (WYSIWYG).

\section{Designing for User Experience: Context Matters}

User experience is defined as "a person's perceptions and responses that result from the use and/or anticipated use of a product, system or service" (ISO 9241-210 2010, p. 7), or as Hassenzahl (2003, p. 31) puts it: "it (user experience) has become a catchphrase, calling for a holistic perspective and an enrichment of traditional quality models with non-utilitarian concepts (...)". User experience therefor describes all effects before, during and after the usage of a product, whereas usability focuses on the actual usage situation. Additionally, user experience extends the purely functional aspects (i.e. pragmatic) by non-utilitarian aspects (i.e. hedonic aspects). The perceived quality of a product (in contrast to the intended product quality by the designer) is heavily depending on the context of use (i.e. factors such as time, space, social factors and so forth).

Particularly the guidelines listed under (10) "hedonic quality" address factors that are not primarily connected to purely functional requirements. For an overall good user experience they have to be taken into account when designing a coffee vending machine, i.e. they are jointly responsible if the customer is likely to choose the same vending machine again. Jordan (2000) lists four parameters to address hedonic qualities, namely socio-pleasure, ideo-pleasure, psycho-pleasure and physio-pleasure. Holt and Lock (2008) took on this approach and developed a pleasure hierarchy including "identifiable pleasure attributes" (Holt \& Lock 2008) to address the four different kind of pleasures (see table 2).

Table 2. Pleasure hierarchy (own illustration based on Holt \& Lock 2008).

\begin{tabular}{|c|c|c|c|}
\hline Socio-pleasure & Ideo-pleasure & Psycho-pleasure & Physio-pleasure \\
\hline $\begin{array}{c}\text { Cooperation and } \\
\text { Collaboration }\end{array}$ & $\begin{array}{c}\text { Individual self- } \\
\text { worth }\end{array}$ & Cognitive arousal & $\begin{array}{c}\text { Sensual stimula- } \\
\text { tion }\end{array}$ \\
\hline $\begin{array}{c}\text { Community and } \\
\text { self-worth }\end{array}$ & Sensual aesthetics & $\begin{array}{c}\text { Progression and } \\
\text { achievement }\end{array}$ & Physical arousal \\
\hline $\begin{array}{c}\text { Love and friend- } \\
\text { ship }\end{array}$ & $\begin{array}{c}\text { Creativity and } \\
\text { expression }\end{array}$ & $\begin{array}{c}\text { Curiosity fulfill- } \\
\text { ment }\end{array}$ & \\
\hline $\begin{array}{c}\text { Helping, giving, } \\
\text { sharing }\end{array}$ & & & \\
\hline
\end{tabular}

Adopting the model to the context of coffee vending machines we can address all four kinds of pleasures: socio-pleasure (drinking coffee can be a social event itself), ideo-pleasure (e.g. offering organic coffee can express individuality and increase one's sense of self-worth), psycho-pleasure (e.g. offering different kinds of flavors for different moods) and physio-pleasure (experiencing tasty, good quality coffee). 


\section{Conclusion}

We used an expert-based heuristic walkthrough to evaluate more than a dozen different models of coffee vending machines, located at a university campus. The resulting usability problems and positive design solutions were documented and served as the basis of our design guidelines. Besides purely functional requirements, hedonic qualities such as an aesthetically pleasant design or the prize and quality of the coffee have to be addressed to provide an overall good user experience.

Although the suggested guidelines address coffee vending machines at first, most of them can also be applied to other kinds of vending and self-service machines. Usability and user experience as a quality of life will become even more important as the computerization of our everyday life increases (ISO 20282-1 2006).

\section{Acknowledgments}

We want to thank all involved colleagues and students for their contribution to this study.

\section{Bibliography}

Böhm, P.: Design-Heuristiken für Alltagsgeräte [Design Heuristics for Everyday Devices]. Master Thesis at the Media Informatics Group, University of Regensburg. To be published on the document server of the University of Regensburg (http://epub.ur.de), Regensburg $\underline{(2011)}$

Bratteberg, I., \& Kristoffersen, S.: Irreversibility and forceback in public interfaces. In: Proceedings of the 5 th Nordic conference on Human-computer interaction building bridges NordiCHI '08 (p. 63). New York (2008)

Camilli, M., Dibitonto, M., Vona, A., Medaglia, C. M., \& Di Nocera, F.: User-centered design approach for interactive kiosks. In: Proceedings of the 9th ACM SIGCHI Italian Chapter International Conference on Computer-Human Interaction Facing Complexity - CHItaly (p. 85). New York (2011)

Connell, I., Blandford, A., Green, T.: CASSM and cognitive walkthrough: usability issues with ticket vending machine. Behaviour and Information Technology 23 (5) 307-320 (2004)

Hassenzahl, M.: The Thing and I: Understanding the Relationship Between User and Product. Funology: from Usability to Enjoyment. Kluwer Academic Publishers, Dordrecht, 31-42 (2003)

Holt, J., Lock, S.: Understanding and Deconstructing Pleasure: A Hierarchical Approach. In: Proceedings of the ACM SIGCHI Conference CHI 2008 (2008)

ISO 20282-1:Ease of operation of everyday products - Part 1: Design requirements for context of use and user characteristics. Beuth, Berlin (2006).

ISO 9241-210: Ergonomics of human-system interaction - Part 210: Human-centred design for interactive systems. Beuth, Berlin (2010)

Jordan, P. W.: Designing pleasurable products. Taylor \& Francis, London (2000)

Lee, D. H.: Consumers' Experiences, Opinions, Attitudes, Satisfaction, Dissatisfaction, and Complaining Behavior with Vending Machines. Journal of Consumer Satisfaction, Dissatisfaction and Complaining Behavior, 16, 178-197 (2003) 
Nielsen, J., Molich, R.: Heuristic evaluation of user interfaces. In: Proceedings of the ACM SIGCHI Conference CHI'90, Seattle, 249-256 (1990)

Norman, D. A.: The design of everyday things. (Reprint.). Basic Books, New York (2002)

Saffer, D.: Designing Devices. Amazon Kindle eBook (2012)

Sears, A.: Heuristic Walkthroughs: Finding the problems without the noise. International Journal of Human-Computer Interaction, 9(3), 213-234 (1997)

Thimbleby, B., Blandford, A., Cairns, P., Curzon, P., Jones, M.: User Interface Design as Systems Design. In: Faulkner, X., Finlay, J., Détienne, F. (eds.).: People and computers XVI: memorable yet invisible. Springer, Berlin (2002)

Villanueva, C. M., Cantor, K. P., King, W. D., Jaakkola, J. JK., Cordier, S., Lynch, C. F., Porru, S., Kogevinas, M.: Total and specific fluid consumption as determinants of bladder cancer risk. International Journal of Cancer 118(8), 2040-2047 (2006)

Wharton C., Rieman, J., Lewis, C., Polson, P.: The cognitive walkthrough method: a practitioner's guide. In: Nielsen, J., Mack, R. (eds.): Usability Inspection Methods, 105-140. John Wiley \& Sons, New York (1994) 